\title{
PDM Field Study in Collaborative Engineering Education - Results from 2016/17
}

\author{
https://doi.org/10.3991/ijoe.v15i04.9753 \\ Andreas Probst ${ }^{(\varpi)}$ \\ HTL Ried, Ried/Innkreis, Austria \\ Andreas.Probst@eduhi.at \\ Martin Ebner, Martin Schön \\ Graz University of Technology, Graz, Austria \\ Detlef Gerhard \\ TU Wien, Vienna, Austria
}

\begin{abstract}
This work describes the research activities performed regarding engineering education at Austrian Federal Colleges of Engineering (HTL) in collaboration with both Graz and Vienna Universities of Technology. To provide assistance to collaboration in engineering education, several Austrians HTLs were introduced to a Product Data Management system (PDM). A field study was conducted in the academic year 2016/17 that will continue in 2017/18 to determine how to utilize this type of software and methodology in order to encourage and improve collaboration between students. This paper presents the initial results of the survey, obtained in the academic year 2016/17 and the impression of the lecturers regarding the degree of teamwork exhibited by students within their design projects.
\end{abstract}

Keywords-Design practice, Product development, Outcomes based assessment, Higher education, Engineering Education, Teamwork, Engineering Collaboration, PDM

\section{Introduction}

Working in teams is a key skill for engineers because coping with complexity in engineering projects demands the contribution of specialists in different engineering disciplines, rather than the work of a single designer [1]. Martinec [2] stated that during conceptualization within design project tasks like goal formulation, ideation and decision-making teamwork are certainly important and need some effort put into them. Therefore, collaboration in engineering education is common practice. Especially in mechanical engineering design education is performed with special tools known as CAD systems, but for collaboration additional tools called Product Data Management systems (PDM) systems are needed. While there are several papers [3], [4], [5], [6] and books which describe the advantages and usage of PDM systems [7] 
there is no existing research about the progress in collaboration of students using PDM tools. The motivation for the research presented in this paper is to obtain knowledge about how to best utilize these types of software and methods to improve inter-student collaboration.

\section{Background and Related Work}

This research work is the follow-up to the research study [9] presented at the International Conference on Interactive Collaborative Learning ICL2017 in Budapest Hungary.

\subsection{Collaboration in engineering education}

When looking at different methodologies for engineering education, ProblemBased learning and Project-Based learning can be identified as the two major approaches within previous research.

Mills et al. [10, p. 8] determine in their paper the difference between ProblemBased learning and Project-Based (PBL) learning in the field of engineering education. They stated that "Project-Based learning is usually accompanied by subject courses (eg maths, physics etc. in engineering), whereas problem-based learning is not". Furthermore, they identified Project-Based learning frequently used in K-12 education.

Looking at teaching, Kolmos [11] identifies different teaching roles. For ProjectBased learning the role of a "product-oriented supervisor" is compared to a "processoriented supervisor" in Problem-Based learning scenarios. Additionally, she identifies a difference at the problem-solving level; that project work has more to do with both problem analysis and problem solution than Problem-Based learning which focuses mainly on problem analysis.

Searching for differences between the two approaches Perrenet et al. [12, p. 348] find "Project-Based learning is more directed to the application of knowledge, whereas Problem-Based learning is more directed to the acquisition of knowledge".

It seems that the Project-Based learning approach is what is generally utilized in Austrian HTLs, especially in labs and engineering design education lessons.

In their paper Johnson and Johnson [13, p. 2] identify five required conditions for team management to get better results than competitive or individual performance".

- Clearly perceived positive interdependence

- Considerable promotive (face-to-face) interaction

- Clearly perceived individual accountability and personal responsibility to achieve the group's goals

- Frequent use of the relevant interpersonal and small-group skills

- Frequent and regular group processing of current functioning to improve the group's future effectiveness" 
Considering this, students improve their teamwork skills, doing educational design projects in groups after starting their third year out of five.

Oakley et al. [14] identify in their paper several basic conditions to turn student groups into effective teams:

- Ensuring that expectations are reasonable by establishing clear guidelines

- Giving team members useful information on team practices that work well before they begin working with one another

- Effectively handling problems with team members

Regarding the optimal team size, they state that there is no consensus in the literature, but most authors agree that the minimum team size for most team tasks is three and the maximum is five. Two people may not provide enough ideas, skills, and approaches to maximize the outcome of the group work. In addition, conflicts among pairs of people tend to be won by the more dominant partner, even if they are wrong. However, if a team consists of six or more individuals, at least one tends to contribute less than the others. In regard to this, the team size for the field study is determined to be three, four or five team members, depending on the overall number of students attending a class.

In their work $\mathrm{Lu}$ et al. [8] distinguishes between coordination, cooperation, and collaboration. Considering his classification (see Table 1) (especially for small student groups') collaboration seems to be the most appropriate form of working on common tasks and objectives. They also state that traditional engineering can be identified as a decision process with many technical aspects or "task work" conducted by individuals, whereas collaborative engineering must also be thought of as a social collaboration for the sake of teamwork and reaching agreement between those involved

Table 1. "Collective human endeavor characteristics" [8, p. 615]

\begin{tabular}{|l|l|l|l|l|}
\hline & \multicolumn{1}{|c|}{ Stakeholder } & \multicolumn{1}{c|}{ Resource } & \multicolumn{1}{c|}{ Goal } & \multicolumn{1}{c|}{ Task Structure } \\
\hline Coordination & Large Community & $\begin{array}{l}\text { Limited and } \\
\text { Exchanged }\end{array}$ & $\begin{array}{l}\text { Multiple \& } \\
\text { Competing }\end{array}$ & $\begin{array}{l}\text { Pre-defined, same layer in } \\
\text { hierarchy, uni-direction }\end{array}$ \\
\hline Cooperation & Mid-size Group & $\begin{array}{l}\text { Limited a } \\
\text { nd } \\
\text { Shared }\end{array}$ & $\begin{array}{l}\text { Multiple \& } \\
\text { Private }\end{array}$ & $\begin{array}{l}\text { Pre-defined, across layers } \\
\text { in hierarchy, bi-direction }\end{array}$ \\
\hline Collaboration & Small Team & $\begin{array}{l}\text { Limited, Shared } \\
\text { Complementary }\end{array}$ & $\begin{array}{l}\text { Single \& } \\
\text { Common }\end{array}$ & $\begin{array}{l}\text { Undefined, non- } \\
\text { hierarchical, multi- } \\
\text { direction }\end{array}$ \\
\hline
\end{tabular}

Furthermore, Lu et al. see "collaborative engineering as the synergy between teamwork and task-work" [8, p. 620]. They observed the common characteristics of successful teams within industry, including: $[8$, p. 610]

- It is best to make joint decisions since these lead to better outcomes than individual decisions.

- Groups are able to be open minded and honest in theirs communications with each other. 
- All team members have the ability to contribute their own creativity in both the creation and claiming of value when making group decisions

Additionally $\mathrm{Lu}$ et al. [8, p. 610] declared "desirable results from a collaborative engineering team should go beyond task-work agreements that meet stakeholders' competing interests and requirements". They also state that teams should avoid limiting their decision-making process. Instead, they should allow themselves to think of multiple alternative possibilities and solutions.

Lu et al. [8, p. 605] also stated "Although we can recognize the good results of successful collaborations, our ability to re-create the desired collaboration process and train engineers to better collaborate with each other is still very limited"

\subsection{PDM in engineering and engineering education}

Although PDM and PLM are commonly used in industry, Small and Medium Enterprises (SME) seem to use such tools only when they are part of a supply pyramid. In this case, the Original Equipment Manufacturer (OEM) and their supplier have to develop together and share product data. Schuh et al. [6, p. 211] report in their publication that a survey "in the automotive industry have shown that there is a wide gap between the current implementation status and the state of the art". Though the research mentioned in this research study was done several years ago, the situation has not changed a lot. Duigou et al. [15] described in their paper framework for modeling to support the use of SMEs as part of the implementation process of PLM systems. Despite these facts, the authors of this paper believe that the single source of data is very important for international operating teams, therefore working with PDM programs has to be trained in engineering education classes.

Mamo et al. [16] described a Global Design Exercise between three universities carried out as a project involving collaborative design, in which, for eight weeks, engineering students from various disciplines and cultural backgrounds participated. They investigated "the patterns in the use of design tools by students in engineering design to collaborate with each other".

One outcome of the project was the information about students' usage of online tools like Skype, Dropbox, Whatsapp, and Facebook together with professional design tools like CAD to solve a given design task. In his research work Barrie [17, p. 1] reports about this Global Design Exercise that the "CAD modelling process was conducted by a single person with inputs from other team members, mostly via Facebook and Skype". This lack of usage of design tools seems to show an urgent need for webbased PDM tools, case of use (usability) and a simple user interface.

Although there have been several efforts to introduce PDM systems and methodologies like concurrent engineering design and development at Austrian HTLs [18] [19] [9], the acceptance among students and staff has been mixed. The benefits for students (like access to data from any place and collaboration with other students) and the benefits for staff (like the possibility of getting information about workload over time, information about the students who have genuinely worked on the project data 
as well as the possibility to administrate projects and access) seem to be opposed by the effort needed to learn an additional program within students education.

\section{Research Questions}

Regarding research work three research questions are specified:

RQ1: Can collaboration within the student groups be easily identified and monitored?

RQ2: What challenges occurred over the course of the field study?

RQ3: How many of the tasks were completed during the allotted time?

Concerning the first research question the different file versions displayed in Figure 1 of each compulsory file from Figure 2 are collected in a database. The question is how often students alternately edit and store the different files given within their task. Evaluating all of the data from each student group will provide information about how students collaborate and how they utilized the PDM system.

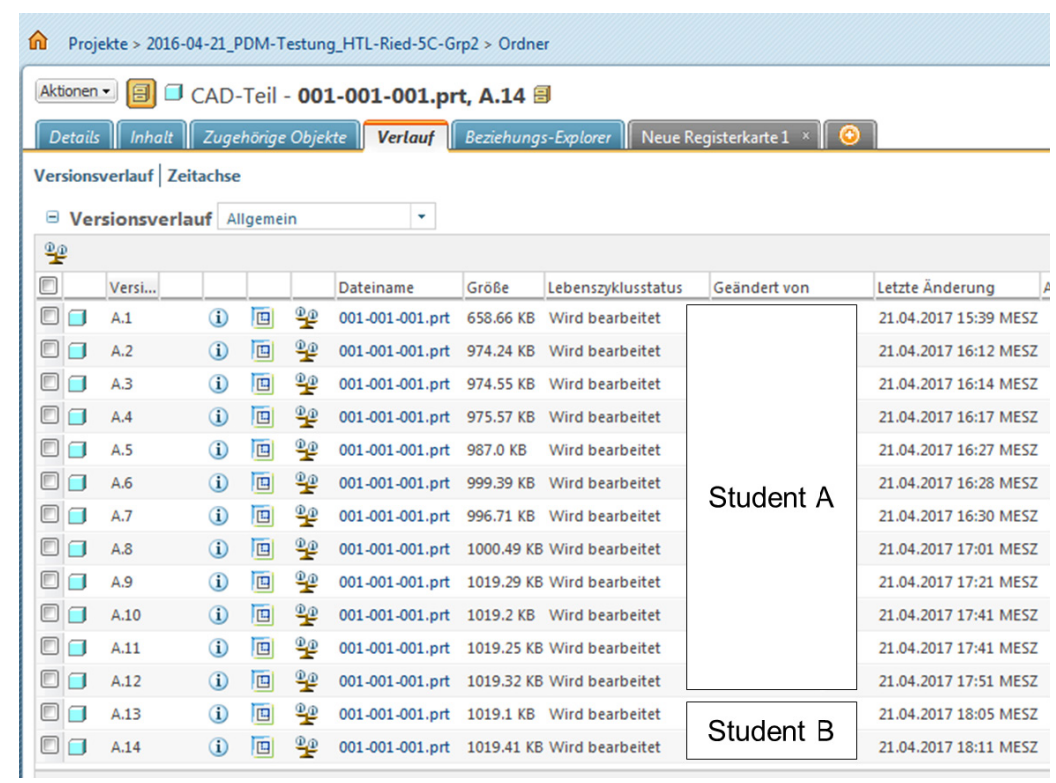

Fig. 1. Different file versions created by two students within PDM database.

The second research question is about difficulties occurring during the field study which could not be identified from looking into the PDM database. For this reason, student notes in Table 9 and teacher's observations and notes are evaluated in order to obtain extra information to be used in the field study.

The third research question regarding the number of completed tasks within the given timeframe will, when combined with the evaluated PDM data, determine if a correlation between the collaboration of the students and the percentage of tasks completed exists. 


\section{$4 \quad$ Research Methodology of PDM Field Study}

\subsection{PDM field study set-up}

The field study was intended to be conducted within 10 Austrian Federal Colleges of Engineering (HTL) [9] but due to daily business reasons only three HTLs participated in the study in the academic year 2016/17. In the academic year 2017/18, the field study is being continued amongst several other HTLs. For the purposes of the field study, students in the participating classes are split into groups of three or four individuals and must solve the given assignment together using the CAD program in conjunction with the PDM software. The students have a maximum of four hours to complete their tasks and receive no instructions on how they should work together.

Design task and deliverables: The design task is a single stage gear transmission (see Figure 2) where some parts like the gearbox housing already exist and are stored within the PDM database. The figure also shows the deliverables for the PDM field study, however stress calculation or any other calculation of any part is not included in the study. Despite teachers not telling them to do so, students split up the work they are assigned to do between themselves and decide how they will collaborate.

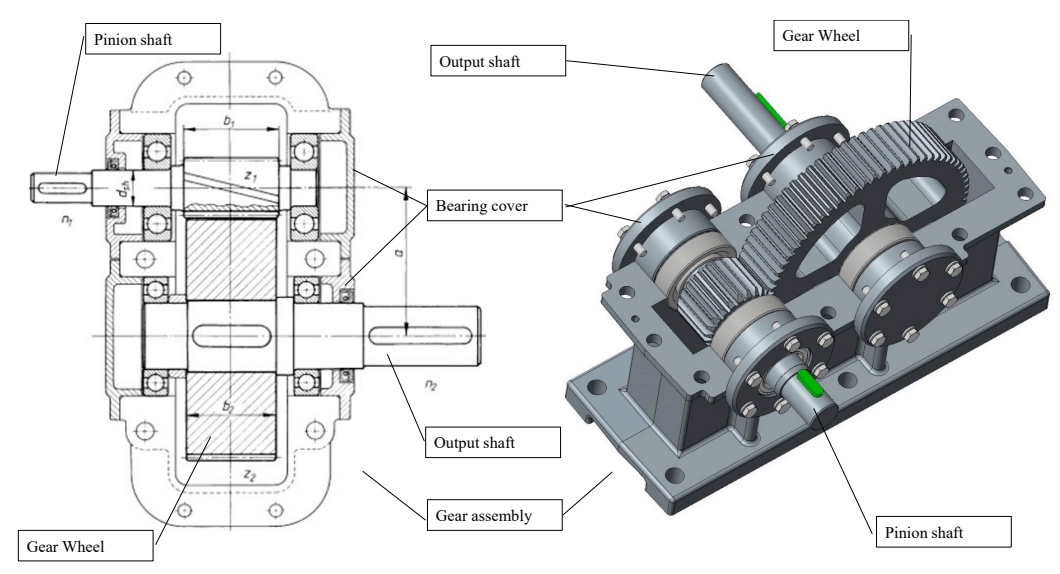

Fig. 2. Design task single stage transmission 2D drawing [20] and 3D CAD model

Instead of giving grades to the student projects, as we first intended [9], the percentage of completion within the task regarding the following aspects is evaluated:

- Parts displayed in the drawings are producible

- Completed dimensions of the parts

- The necessary surface symbols and tolerances are displayed on the drawings

Parameter used for collecting data: For each group the following data are collected. 
Table 2. Parameter used for calculation

\begin{tabular}{|l|l|l|}
\hline No. & \multicolumn{1}{|c|}{ Parameter description } & \multicolumn{1}{c|}{ Sub parameter } \\
\hline 1 & $\begin{array}{l}\text { Austrian Federal Colleges of Engineering } \\
\text { HTL) }\end{array}$ & \\
\hline 2 & Group Nr. & \\
\hline 3 & Students / group & \\
\hline 4 & Female students / group & \\
\hline 5 & Percentage of collaboration & \\
\hline 6 & experience w. PDM [month] & \\
\hline 7 & Percentage of completion & Number of occurrences [quantity] \\
\hline 8 & Saved file versions / group & Time for correction [minutes] \\
\hline 9 & Improvements within data conflicts & Number of occurrences [quantity] \\
\hline 10 & Improvements within data conflicts & Time for correction [minutes] \\
\hline 11 & 3D interface problems & Number of discussions [quantity] \\
\hline 12 & 3D interface problems & Time for each discussion [minutes] \\
\hline 13 & Coordination concerning 2d working draft & Number of occurrences [quantity] \\
\hline 14 & Coordination concerning 2d working draft & Time for correction [minutes] \\
\hline 15 & Working on the same parts or assemblies & \\
\hline 16 & Working on the same parts or assemblies & $\begin{array}{l}\text { I=winter semester / } \\
\text { 2=summer semester }\end{array}$ \\
\hline 17 & Duration of field study & \\
\hline 18 & Time field study started & \\
\hline 19 & Semester of field test & \\
\hline 20 & HTL year & \\
\hline & & \\
\hline
\end{tabular}

PDM field study data: In Table 3 the collected data from the field study so far are displayed. Data were collected from three different HTLs among four classes with a total of 18 groups consisting of three or four students each. The overall number of students was 68 which included three female students; the subjects of these classes are Mechanical Engineering (MB) or Mechatronics (ME).

Table 3. Overview involved HTL classes PDM field study

\begin{tabular}{|l|c|c|c|c|c|}
\hline \multicolumn{1}{|c|}{ Colleges / HTL } & Graz & Wien3 & Wien3 & Ried & Total / remarks \\
\hline Subject & MB & ME & ME & MB & \\
\hline HTL year & 3 rd & 4 th & 4 th & 5 th & \\
\hline Students' average age & 16 years & 17 years & 17 years & 18 years & \\
\hline Experience w. PDM & 3 & 2 & 2 & 1 & {$[$ months] } \\
\hline Groups / class & 4 & 7 & 5 & 2 & 18 \\
\hline Students / group & 4 & $4 / 3$ & 3 & 4 & 68 \\
\hline Students total & 16 & 26 & 18 & 8 & 3 \\
\hline Female students & 3 & 0 & 0 & 0 & {$[\mathrm{hh}: \mathrm{min}]$} \\
\hline Evaluation time & $3: 05$ & $3: 25$ & $3: 25$ & $3: 15$ & \\
\hline
\end{tabular}

Evaluation of collaboration in field study: In the academic year 2016/17, three Austrian HTLs with 18 groups and a total of 68 students participated in the field study. Each HTL class was split into groups of three or four individual students, with each group being giving a single PDM project to work on. The CAD and PDM data obtained from each student group stored within the PDM system were then collected and all of the data were collectively analyzed anonymous through a process of pairreviewing. Table 4 portrays one such evaluated example of a PDM project from a four-student group. For example, the fifth row indicates that the students managed to create the deliverable of the 3D-CAD model of the output shaft and thus completed 
the task entirely. In the table, "A" represents student A, "B" student B etc., therefore one can see that only student $\mathrm{D}$ worked with this file and stored it in two versions.

Table 4. Evaluation saved file versions from PDM database

\begin{tabular}{|c|c|c|c|c|c|c|c|c|c|c|c|}
\hline HTL-nnn-Group-x & \multirow[b]{2}{*}{ File type } & \multirow{2}{*}{$\begin{array}{r}\text { Task \% } \\
\text { finished }\end{array}$} & \multicolumn{9}{|c|}{ File version } \\
\hline Deliverable & & & 1 & 2 & 3 & 4 & 5 & 6 & 7 & 8 & 9 \\
\hline Gear assembly & assembly & 100 & $\mathrm{~B}$ & $\mathrm{~B}$ & $\mathrm{~B}$ & $\mathrm{~B}$ & $\mathrm{~B}$ & $\mathrm{~B}$ & $\mathrm{~B}$ & $\mathrm{~B}$ & \\
\hline & drawing & 100 & $\mathrm{~B}$ & $\mathrm{~B}$ & $\mathrm{~B}$ & $\mathrm{~B}$ & & & & & \\
\hline Output shaft & 3D part & 100 & $\mathrm{D}$ & $\mathrm{D}$ & & & & & & & \\
\hline & drawing & 100 & $\mathrm{D}$ & & & & & & & & \\
\hline
\end{tabular}

To evaluate the collaboration for each deliverable (see Table 4) we determine which file version was created by which student and an expectancy value is calculated by dividing the total file versions by the number of students. Afterwards a $\mathrm{Chi}^{2}$ function is calculated for each student's task as well as the sum of all $\mathrm{Chi}^{2}$ Values. Lastly, the value for the $\mathrm{p}$ - significance is calculated. An example of collected and calculated data for the 3D CAD part of the pinion shaft from Table 4 is shown in Table 5.

Table 5. Evaluation example of students' collaboration

\begin{tabular}{|c|c|c|c|c|c|c|c|c|c|c|c|}
\hline \multicolumn{3}{|c|}{$\begin{array}{c}\text { File versions } \\
\text { /Student }\end{array}$} & $\begin{array}{c}\text { Total } \\
\text { versions }\end{array}$ & $\begin{array}{c}\text { Expectancy } \\
\text { value }\end{array}$ & \multicolumn{4}{c|}{ Chi $^{2}$ / Student } & Total & $\begin{array}{c}\text { File versions } \\
\text { /Student }\end{array}$ \\
\hline 1 & 2 & 3 & 4 & & & 1 & 2 & 3 & 4 & & \\
\hline 7 & 0 & 0 & 2 & 9 & 2,25 & 10 & 2,3 & 2,3 & 0 & 14,6 & 0,0007 \\
\hline
\end{tabular}

A high $\mathrm{Chi}^{2}$ value means a deviation of uniform distribution as well as a low psignificance value, and a low collaboration between students for editing and saving data from the given field test task.

\subsection{Evaluation of occurring difficulties in field study}

Over the course of the study students were required to take written notes of certain effects which are then evaluated, as seen in Table 6 . This gives the opportunity to get information in addition to that gained from the PDM database.

Table 6. Overview pattern of students' notes for PDM field study

\begin{tabular}{|c|c|c|c|}
\hline Measurable effect & No. & Collected data & Remarks \\
\hline \multirow{2}{*}{$\begin{array}{l}\text { Improvements within } \\
\text { data conflicts }\end{array}$} & 9 & Number of occurrences [quantity] & \\
\hline & 10 & Time for correction [minutes] & \\
\hline \multirow[t]{2}{*}{ 3D interface problems } & 11 & Number of occurrences [quantity] & \multirow{2}{*}{$\begin{array}{l}\text { 3D parts and assembly } \\
\text { do not match }\end{array}$} \\
\hline & 12 & Time for correction [minutes] & \\
\hline \multirow{2}{*}{$\begin{array}{l}\text { Coordination concern- } \\
\text { ing } 2 \mathrm{~d} \text { working draft }\end{array}$} & 13 & Number of discussions [quantity] & \multirow{2}{*}{$\begin{array}{l}\text { Students have to carry } \\
\text { out and adapt a work- } \\
\text { ing draft }\end{array}$} \\
\hline & 14 & Time for each discussion [minutes] & \\
\hline \multirow{2}{*}{$\begin{array}{l}\text { Working on the same } \\
\text { parts or assemblies }\end{array}$} & 15 & Number of occurrences [quantity] & \multirow{2}{*}{$\begin{array}{l}\text { Due to a PDM concept } \\
\text { only one person can } \\
\text { work on one part at } \\
\text { one time }\end{array}$} \\
\hline & 16 & Time for correction [minutes] & \\
\hline $\begin{array}{l}\text { Individual students } \\
\text { notes }\end{array}$ & & Effects and remarks & individual evaluation \\
\hline
\end{tabular}


The quantity and minutes are collected from every student's individual notes but are only processed for a whole group. Teachers were also required to make note of several effects such as the start and end time of the field study as well as individuals' notes like problems with students' computers or students leaving the field study early. This will give more accurate information about whether groups are performing efficiently or not.

\subsection{Evaluation of PDM field study completed tasks}

The evaluation of the percentage of finished tasks (see Table 4) is done anonymously by two teachers according to given criteria that students and teacher know from the beginning of the test. These criteria are:

- Assemblies are complete

- No interface problems like intersections between parts are occurring

- Parts are producible

- Dimensioning of the parts in the drawings is complete

- Expedient surface symbols and tolerances are on the drawings

- No geometrical dimensions and tolerances are needed in the drawings

- Bill of material is present and completed (e.g. material, good part names, ...)

\section{$5 \quad$ PDM Field Study Results}

\subsection{Results for collaboration in field study}

A heuristic method of a principal component analysis is used to present the data matrix more simply and manageably, see Table 7 . The first four principal components (Table 7, rows 1 to 4 ) describe 84.55 percent of the total variance. In order to interpret these components, the correlations of the original variables with these most important components 1 to 4 are considered.

For the interpretation, the Variamax rotation method (see Table 8.) has proven to clearly allocate the variables to one of the four factors. Values below 0.25 are not shown in the rotated component matrix.

Since we are particularly interested in the degree of collaboration, the columns with components 3 and 4 in Table 8 are especially interesting since the parameter grade of collaboration only occurs there. In column 4 , a higher degree of collaboration is associated with group size and duration of the experience with PDM programs. Since the group size varies only between groups consisting of 3 or 4 group members, this means that the groups of four seem to have a higher degree of collaboration than the groups of three.

As a matter of course, an odd group size is recommended for a board of management because it enables quicker decision making. In the case of a vote, a majority will inevitably arise. But what about cooperation? 
Table 7. Principal component analysis based on parameters and collected data

\begin{tabular}{|l|c|c|c|}
\hline $\begin{array}{c}\text { Principal } \\
\text { component }\end{array}$ & Sum & $\begin{array}{c}\text { Variance } \\
{[\%]}\end{array}$ & $\begin{array}{c}\text { Accumulated } \\
{[\%]}\end{array}$ \\
\hline 1 & 6,434 & 40,211 & 40,211 \\
\hline 2 & 3,851 & 24,071 & 64,282 \\
\hline 3 & 1,971 & 12,32 & 76,602 \\
\hline 4 & 1,272 & 7,953 & 84,555 \\
\hline 5 & 0,776 & 4,852 & 89,407 \\
\hline 6 & 0,697 & 4,356 & 93,763 \\
\hline 7 & 0,514 & 3,211 & 96,974 \\
\hline 8 & 0,219 & 1,372 & 98,346 \\
\hline 9 & 0,111 & 0,693 & 99,039 \\
\hline 10 & 0,092 & 0,578 & 99,617 \\
\hline 11 & 0,044 & 0,275 & 99,892 \\
\hline 12 & 0,016 & 0,101 & 99,993 \\
\hline 13 & 0,001 & 0,005 & 99,999 \\
\hline 14 & 0 & 0,001 & 100 \\
\hline 15 & $4,52 \mathrm{E}-05$ & 0 & 100 \\
\hline 16 & $-1,41 \mathrm{E}-15$ & $-8,83 \mathrm{E}-15$ & 100 \\
\hline
\end{tabular}

Table 8. Variamax rotation matrix

\begin{tabular}{|c|c|c|c|c|}
\hline & \multicolumn{4}{|c|}{ Component } \\
\hline & 1 & 2 & 3 & 4 \\
\hline Students / group & $-0,359$ & & & 0,634 \\
\hline Female students / group & & 0,513 & 0,499 & \\
\hline Percentage of collaboration & & & 0,526 & 0,581 \\
\hline Experience w. PDM [months] & & & 0,977 & \\
\hline Percentage of completion & & 0,911 & & \\
\hline Saved file versions / group & & 0,889 & & \\
\hline $\begin{array}{l}\text { Improvements w. data conflicts -Number of occurrences } \\
\text { [quantity] }\end{array}$ & 0,536 & $-0,454$ & & 0,496 \\
\hline $\begin{array}{l}\text { Improvements w. data conflicts - Time for correction } \\
\text { [minutes] }\end{array}$ & 0,757 & $-0,47$ & & 0,345 \\
\hline 3D interface problems - Number of occurrences [quantity] & 0,901 & & 0,381 & \\
\hline 3D interface problems - Time for correction [minutes] & 0,941 & & & \\
\hline $\begin{array}{l}\text { Coordination concerning } 2 \mathrm{~d} \text { working draft - Number of } \\
\text { discussions [quantity] }\end{array}$ & 0,945 & & & \\
\hline $\begin{array}{l}\text { Coordination concerning } 2 \mathrm{~d} \text { working draft - Time for each } \\
\text { discussion [minutes] }\end{array}$ & 0,956 & & & \\
\hline $\begin{array}{l}\text { Working on the same parts or assemblies - Number of occur- } \\
\text { rences [quantity] }\end{array}$ & 0,494 & & & 0,777 \\
\hline $\begin{array}{l}\text { Working on the same parts or assemblies - Time for correc- } \\
\text { tion [minutes] }\end{array}$ & 0,793 & $-0,455$ & & 0,359 \\
\hline Duration of field study & & $-0,608$ & $-0,501$ & $-0,486$ \\
\hline Semester & & & $-0,977$ & \\
\hline
\end{tabular}

In an older study [21] 31 studies were reviewed with the conclusions: ,group size is an important variable which should be taken into account in any theory of group behavior, and future research on group size should proceed more systematically than in the past. There is no specified group size for most effective task performance."

Intuitive theories regarding even numbers, odd numbers, and groups find that even numbered groups are more harmonious. Menon and William Phillips [22] found ,that people view even numbers more favorably than odd numbers and predict that evensized groups are more peaceful than odd-sized groups. However, Study 2 found that 
three- and four-person groups without conflict did not differ, but three-person groups with coalitions (two vs. one) produced more positive relationships than four-person groups with coalitions (both two vs. two and three vs. one)."

On the site "How to Design Small Decision Making Groups" (http://www.intuitor.com/statistics/SmallGroups.html) we find „Rules for Optimizing Small Groups“ and the recommendation „Groups should have an odd number of members. This prevents ties and improves the odds of making a correct decision when using majority rules."

We see: There is no specified group size for effective task performance. Obviously, it depends on the situation. According to our data, groups with four members work together more efficiently than those with three. However, the data base is still very thin.

For the next field study in the academic year $2017 / 18$ we plan to divide the students into equal numbers of groups of three and four.

\subsection{Results regarding difficulties in field study}

There are groups without any values and groups with extremely high values. The first groups (Graz groups 1 to 4, Wien3 groups 1 to 6 and Ried groups 1 and 2) had reported problems using PDM functionality. Meanwhile, it is possible that the HTL Wien 3 groups 7 to 15 did not have enough time to make notes. In particular, group 4 of HTL Wien 3 had reported 22 issues connected with data conflicts (Table 9, parameters 9 and 10), which took 300 minutes of work on the problems connected with PDM. Additionally, they reported 23 occurrences connected with 3D interface problems (Table 9, parameters 11 and 12) which took 360 minutes to work on a solution.

Table 9. Difficulties measured during field test over all groups

\begin{tabular}{|c|c|c|c|c|c|c|c|c|}
\hline \multirow[b]{2}{*}{$H T L$} & \multirow[b]{2}{*}{ Grp. } & \multicolumn{7}{|c|}{ Parameters of Table 2} \\
\hline & & $P 9$ & $P 10$ & $P 11$ & P12 & $P 13$ & $P 14$ & $P 15$ \\
\hline Graz & 1 & 2 & 4 & 8 & 31 & 12 & 100 & 6 \\
\hline Graz & 2 & & & 8 & 80 & 7 & 47 & \\
\hline Graz & 3 & 13 & 115 & 8 & 82 & 6 & 34 & 12 \\
\hline Graz & 4 & 12 & 20 & 9 & 46 & 4 & 12 & 5 \\
\hline Wien3 & 1 & 30 & 210 & & & & & 6 \\
\hline Wien3 & 3 & 6 & 60 & & & & & 8 \\
\hline Wien3 & 4 & 22 & 300 & 23 & 360 & 31 & 260 & 8 \\
\hline Wien3 & 5 & & & 1 & 3 & & & \\
\hline Wien3 & 6 & & & & & 12 & 80 & 1 \\
\hline Wien3 & 7 & & & & & & & \\
\hline Wien3 & 8 & & & & & & & \\
\hline Wien3 & 11 & & & & & & & \\
\hline Wien3 & 12 & & & & & & & \\
\hline Wien3 & 13 & & & & & & & \\
\hline Wien3 & 14 & & & & & & & \\
\hline Wien3 & 15 & & & & & & & \\
\hline Ried & 1 & 1 & 60 & & & 4 & 40 & 4 \\
\hline Ried & 2 & 4 & 30 & & & 6 & 45 & 5 \\
\hline Average & & 5,00 & 44,39 & 3,17 & 33,44 & 4,56 & 34,33 & 3,06 \\
\hline
\end{tabular}


Looking into the evaluated data, while being a group of three students with 2 months experience in PDM, only two students worked on the project, whereas the percentage of finished tasks was with $19,6 \%$ significantly below the average of $62,58 \%$ for all groups (see Table 10). Looking into the individual students' notes, it seems the students especially had problems working with the PDM system (name conflicts, check-in CAD-files, check-out CAD-files, synchronizing the workspaces both local and on the server), whereas using CAD was no issue. In contrast, the students of HTL Ried, who were in their last year at HTL and had one month of experience with PDM (the lowest value in the field study), had significantly fewer problems using the PDM system.

\subsection{Results of PDM field study completed tasks}

Table 10. Evaluation of finished tasks for all groups

\begin{tabular}{|l|l|c|}
\hline & & \% finished \\
\hline assembly & 3D Gear assembly & 67,17 \\
\hline drawing & 2D Gear assembly & 34,72 \\
\hline 3D part & 3D Output shaft & 87,72 \\
\hline drawing & 2D Output shaft & 34,94 \\
\hline 3D part & 3D Gear Wheel & 99,17 \\
\hline drawing & 2D Gear Wheel & 22,44 \\
\hline 3D part & 3D Pinion Shaft & 90,00 \\
\hline drawing & 2D Pinion Shaft & 46,39 \\
\hline 3D part & 3D Bearing Cover 1 & 84,44 \\
\hline drawing & 2D Bearing Cover 1 & 56,39 \\
\hline 3D part & 3D Bearing Cover 2 & 80,28 \\
\hline drawing & 2D Bearing Cover 2 & 35,56 \\
\hline 3D part & 3D Bearing Cover 3 & 70,56 \\
\hline 3D part & 3D Bearing Cover 4 & 66,39 \\
\hline & Average & 62,58 \\
\hline
\end{tabular}

Table 10 and Figure 3 give an overview about completion rates of each task for all groups as well as the average of completion at $62,58 \%$.

Comparing the percentages of task completion it can be identified that $3 \mathrm{D}$ parts and assemblies over all projects done are completed at an average high level of $80,72 \%$ whereas the $2 \mathrm{D}$ drawings are completed with an average of $38,41 \%$. Overall the tasks are completed with an average of $62,58 \%$, which is less than can be observed in common education design projects and may be an impact of stress during the field study. 

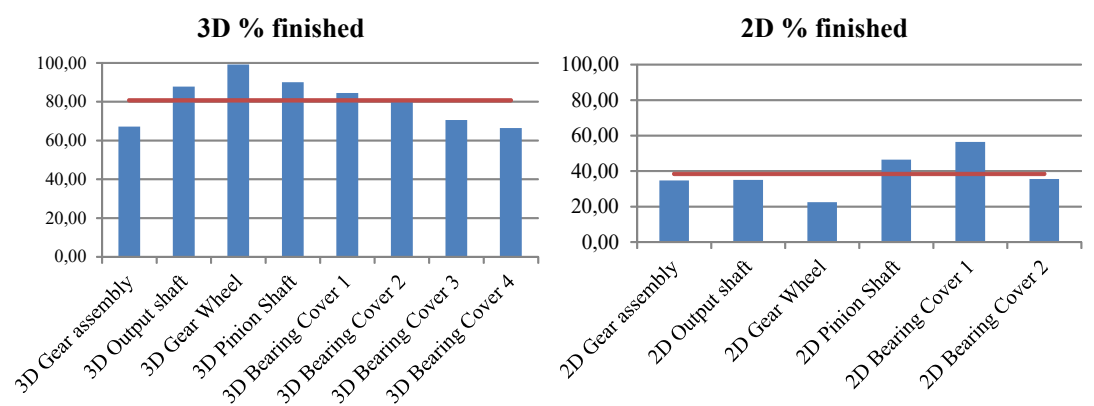

Fig. 3. Comparison of finished 3D and 2D field study tasks

\subsection{Results for research questions}

Results RQ1: Is collaboration identifiable within the student groups? Concerning RQ1 collaboration can be observed, although the correlation with group size needs additional field tests and evaluation.

Results RQ2: What difficulties occurred during the field study? It can be observed that some student groups had problems using the PDM software, whereas other student groups left no information to evaluate. Due to these problems, there seems to be a growing need for user-friendly and simple-to-use interfaces [23].

Results RQ3: How many tasks were completed in the given time? Looking at RQ3, it can be observed that the 3D parts and assemblies are completed at a higher level compared to the 2D drawings. This is unsurprising to the authors, since generating drawings takes more time due to the need to consider several engineering standards.

\section{Conclusion and Further Work}

Collaborative engineering is an increasing part of daily engineering work, which will get more important in the near future, due to worldwide linked development and production in industry. Therefore, introducing and using PDM programs to support students work on collaborative engineering seems to be a good way to prepare students for the requirements of the labor market.

The PDM Field Study tests are ongoing in the current academic year 2017/18 to complete the data set obtained so far. There will be a focus especially on the second research question about difficulties occurring during the tests, to figure out and if possible mitigate the students' problems with PDM programs.

Despite the few successes that have been achieved so far, it will take additional efforts to introduce PDM methodology into engineering education. Starting with introducing PDM into mechanical engineering design education, it will be necessary to introduce it to electrical and mechatronics engineering as well. Due to this, students will learn how to develop products within collaborative engineering, which will be a key success factor in a changing industrial environment. 


\section{$7 \quad$ References}

[1] A. Ensici, P. Badke-Schaub, N. Bayazıt, and K. Lauche, "Used and rejected decisions in design teamwork," CoDesign, vol. 9, no. 2, pp. 113-131, 2013. https://doi.org/10.10 $\underline{80 / 15710882.2013 .782411}$

[2] T. Martinec, S. Škec, and M. Štorga, "Exploring the decomposition of team design activity," in DS 87-3 Proceedings of the 21st International Conference on Engineering Design (ICED 17) Vol 3: Product, Services and Systems Design, Vancouver, Canada, 2125.08.2017, 2017.

[3] J. Feldhusen, M. Löwer, A. Brezing, and J. Neis, "PLM-enhanced engineering education," in Proceedings of E\&PDE 2010 When design education and design research meet: Proceedings of the 12th International Conference on Engineering and Product Design Education, Norwegian University of Science and Technology (NTNU) Trondheim, Norway, 2nd - 3rd September 2010 ; [E\&PDE], 2010, pp. 598-604.

[4] M. Geier and J. Steffen, "Establishing CAD and PDM as Part of Engineering Education in Large Classes for Undergraduate Students," in Proceedings of E\&PDE 2012 Design education for future wellbeing: Proceedings of the 14th International Conference on Engineering and Product Design Education, Artesis University College, Antwerp, Belgium, 6th - 7th September 2012, 2012.

[5] M. Abramovici and A. Youssef, "Next Generation Product Lifecycle Management (PLM).," in Integration of Practice-Oriented Knowledge Technology: Trends and Prospectives, Springer, Berlin Heidelberg, Germany, 2013, pp. 143-156. https://doi.org/10. 1007/978-3-642-34471-8 12

[6] G. Schuh, H. Rozenfeld, D. Assmus, and E. Zancul, "Process oriented framework to support PLM implementation," Computers in Industry, vol. 59, no. 2-3, pp. 210-218, 2008. https://doi.org/10.1016/j.compind.2007.06.015

[7] M. Eigner and R. Stelzer, Product Lifecycle Management: Ein Leitfaden für Product Development und Life Cycle Management, 2nd ed. Dordrecht: Springer, 2013.

[8] S.C.-Y. Lu, W. Elmaraghy, G. Schuh, and R. Wilhelm, "A SCIENTIFIC FOUNDATION OF COLLABORATIVE ENGINEERING," CIRP Annals, vol. 56, no. 2, pp. 605-634, 2007. https://doi.org/10.1016/i.cirp.2007.10.010

[9] A. Probst, D. Gerhard, and M. Ebner, "PDM field study and evaluation in collaborative engineering education," in Proceedings of the 20th ICL Conference, Budapest, Hungary, 2017.

[10] J. E. Mills and D. Treagust, "ENGINEERING EDUCATION - IS PROBLEMBASED OR PROJECT-BASED LEARNING THE ANSWER?," in AUSTRALASIAN JOURNAL OF ENGINEERING EDUCATION, AAEE 2003, online publication, 2003.

[11] A. KOLMOS, "Reflections on Project Work and Problem-based Learning," European Journal of Engineering Education, vol. 21, no. 2, pp. 141-148, 2010.

[12] J. C. Perrenet, P. A. J. Bouhuijs, and J. G. M. M. Smits, "The Suitability of Problem-based Learning for Engineering Education: Theory and practice," Teaching in Higher Education, vol. 5, no. 3, pp. 345-358, 2000. https://doi.org/10.1080/713699144

[13] R. T. Johnson and D. W. Johnson, "AN OVERVIEW OF COOPERATIVE LEARNING," in Creativity and Collaborative Learning, Baltimore: Brookes Press, 1994, pp. 1-21.

[14] B. Oakley, R. M. Felder, R. Brent, and I. Elhajj, "Turning student groups into effective teams," Journal of student centered learning, vol. 2, no. 1, pp. 9-34, 2004.

[15] J. Le Duigou, A. Bernard, and N. Perry, "Framework for Product Lifecycle Management integration in Small and Medium Enterprises Networks," Computer-Aided Design and Applications, vol. 8, no. 4, pp. 531-544, 2011. https://doi.org/10.3722/cadaps.2011.531-544 
[16] J. Mamo et al., "USING ENGINEERING DESIGN TOOLS IN MULTIDISCIPLINARY DISTRIBUTED STUDENT TEAMS," in Great expectations: design teaching, research \& enterprise: Proceedings of the 17th International Conference on Engineering and Product Design Education, Loughborough Design School, University of Loughborough, United Kingdom, 3rd-4th September 2015, 2015.

[17] J. Barrie, "APPLICATIONS FOR CLOUD-BASED CAD IN DESIGN EDUCATION AND COLLABORATION," in Great expectations: design teaching, research \& enterprise: Proceedings of the 17th International Conference on Engineering and Product Design Education, Loughborough Design School, University of Loughborough, United Kingdom, 3rd4th September 2015, 2015.

[18] A. Probst, "Introducing PLM at Austrian Secondary Colleges of Engineering," in Proceedings of 2015 International Conference on Interactive Collaborative Learning (ICL), Florence, Italy, 2015, pp. 327-329. https://doi.org/10.1109/ICL.2015.7318047

[19] A. Probst, D. Gerhard, S. Bougain, and C. Nigischer, "Continuous Research and Development Partnership in Engineering Education," in Proceedings of the 19th ICL Conference, Belfast, UK, 2016, pp. 7-21.

[20] W. Matek, D. Muhs, and H. Wittel, Roloff/Matek Maschinenelemente Aufgabensammlung, 6th ed.: Friedr. Vieweg \& Sohn, 1984.

[21] E. J. Thomas and C. F. Fink, "Effects of group size," Psychological bulletin, vol. 60, no. 4, pp. 371-384, 1963. https://doi.org/10.1037/h0047169

[22] T. Menon and K. Williams Phillips, "Getting Even vs. Being the Odd One Out: Conflict and Cohesion in Even and Odd Sized Groups," SSRN Journal, 2008.

[23] P. de Pinel, N. Maranzana, F. Segonds, S. Leroux, and V. Frerebeau, "Proposition of Ergonomic Guidelines to Improve Usability of PLM Systems Interfaces," in IFIP Advances in Information and Communication Technology, v.409, Product Lifecycle Management for Society: 10th IFIP WG 5. 1 International Conference, PLM 2013, Nantes, France, July 810, 2013, Proceedings, A. Bernard, L. Rivest, and D. Dutta, Eds., Berlin/Heidelberg: Springer Berlin Heidelberg, 2013, pp. 530-539. https://doi.org/10.1007/978-3-642-41501$\underline{253}$

\section{Authors}

Andreas Probst is with the HTL Ried a Technical Secondary College of Engineering, Ried, 4910 Ried / Innkreis, Austria

Martin Ebner is with the Educational Technology, TU Graz - Graz University of Technology, 8010 Graz, Austria

Martin Schön is with the Educational Technology, TU Graz - Graz University of Technology, 8010 Graz, Austria

Detlef Gerhard is with the Mechanical Engineering Informatics and Virtual Product Development, TU Wien - Vienna University of Technology, 1040 Wien, Austria

Article submitted 31 October 2018. Resubmitted 29 November 2018. Final acceptance 03 December 2018. Final version published as submitted by the authors. 